\title{
TERRITORIO Y SABER EN DISPUTA. LA CONTROVERSIA LIMÍTROFE CHILENO-ARGENTINA SOBRE LOS ANDES
}

\author{
Rafael Sagredo Baeza \\ Pontificia Universidad Católica de Chile \\ rsagredo@uc.cl
}

Recibido: 24 febrero 2016 ; Aceptado: 22 junio 2016.

\begin{abstract}
Cómo citar este artículo/Citation: Sagredo Baeza, Rafael (2016), "Territorio y saber en disputa. La controversia limítrofe chilenoargentina sobre los Andes", Asclepio, 68 (2): p152. doi: http://dx.doi.org/10.3989/asclepio.2016.24

RESUMEN: Utilizando las alternativas de la disputa fronteriza entre Argentina y Chile en la Patagonia, se ofrece una reflexión y ejemplo del uso del saber geográfico para la reivindicación de soberanías territoriales. Con los presupuestos de la historia social de la ciencia y de la historia cultural, se muestran los condicionamientos que influyeron en los argumentos de las partes, como en la resolución política de una querella territorial que hace más de cien años, como en la actualidad, obligó a Chile a recurrir a instancias internacionales para determinar sus límites y asegurar derechos. Una situación que primero implicó resolver sobre el conocimiento geográfico de la naturaleza disputada, tarea que sin embargo no garantizó asegurar la pretensión nacional pues, en definitiva, el árbitro llamado a decidir no falló basándose solo en el conocimiento adquirido.
\end{abstract}

PALABRAS CLAVE: Demarcación de límites; Andes Patagónicos; Chile; Argentina; Conocimiento científico.

\section{TERRITORY AND KNOWLEDGE IN CONFLICT. THE BORDER DISPUTE OF CHILE AND ARGENTINA IN THE ANDES}

ABSTRACT: Through the study of the border dispute between Argentina and Chile in Patagonia, the article offers a reflection and an example of the use of geographical knowledge in claiming territorial sovereignty. Based on the social history of science and cultural history, it presents the conditionings that influenced the arguments of both countries, and the political resolution of a territorial quarrel that over a hundred years ago, and also nowadays, forced Chile to resort to international bodies to determine its limits and ensure its rights. This situation implied a decision on the geographical knowledge of the disputed nature. This argument, however, did not bolster the Chilean position, since the referee called upon to decide the dispute, after revised several sources and not only the geographical knowledge claimed by Chile.

KEYWORDS: Boundary Demarcation; Patagonic Andes; Chile; Argentina; Scientific Knowledge.

Copyright: ( 2016 CSIC. Este es un artículo de acceso abierto distribuido bajo los términos de la licencia Creative Commons Attribution (CC BY) España 3.0. 


\section{PRESENTACIÓN}

La conclusión del reconocido geógrafo Thomas $\mathrm{H}$. Holdich, asentada en el texto que escribió luego de su participación como árbitro en la disputa limítrofe que enfrentó a Argentina y Chile a fines del siglo XIX, resulta una elocuente expresión del problema que abordaremos. En su obra The Countries of the King 's Award, publicada en 1904 y traducida en 1958 como ¿Territorio en disputa?, se lee: «Difícilmente un término geográfico que define una configuración de la naturaleza presenta bajo todas las condiciones una sola e inalterable interpretación» (Holdich, 1958, p. 43)².

La constatación del inglés, cuya experiencia como geógrafo y perito de límites está acreditada tanto por sus numerosos escritos, libros y comisiones, como por los honores que recibió, entre ellos presidente de la Royal Geographical Society, refleja de manera muy elocuente la situación y dificultades que enfrentaron Argentina y Chile luego de 1881, cuando emprendieron la demarcación de una frontera que el Tratado de límites del año 1881 había establecido en la cordillera de los Andes con la siguiente redacción: "La línea fronteriza correrá por las cumbres más elevadas de dicha Cordillera que dividan las aguas y pasará por entre las vertientes que se desprenden a un lado y otro».

Con el referido acuerdo, Chile y Argentina pretendieron resolver de una vez las querellas territoriales que los enfrentaban desde la década de 1840, recurriendo no solo a un principio del derecho internacional entonces aceptado por la comunidad de las naciones, sobre todo, a un fenómeno natural que también se apreciaba como una barrera entre las dos repúblicas; una realidad geográfica imposible de manipular, inconmovible, obvia, evidente, identificable por cualquiera; símbolo de la solidez y muy fácil de reconocer por los encargados de trazar sobre su superficie la demarcación que separaría los respectivos espacios nacionales.

Sin embargo, la tarea de los peritos de límites experimentó numerosas dificultades derivadas de las diferencias respecto de lo que argentinos y chilenos entendían por cordillera de los Andes, y con ellas, de los espacios que cada uno reivindicaba como propios. En rigor, fue imposible delimitar la línea fronteriza debido a los desacuerdos entre los científicos y políticos al servicio de uno y otro Estado, hecho que los llevó a recurrir a un tercero, el árbitro inglés, que fue quien en definitiva resolvió el curso de la frontera luego de estudiar el caso, atender a los argumentos de las partes y visitar la principal región objeto de la controversia, los Andes Patagónicos, en el extremo sur de
América del Sur. Una zona, a partir aproximadamente del paralelo 470 de latitud sur, en que las imponentes y monolíticas formas de los Andes se fragmentan por efecto de la erosión, la acción de los hielos y los movimientos de la corteza terrestre, dando lugar a múltiples formas del relieve, algunas inundadas por el agua, donde, si hay algo seguro, es que las más altas cumbres no dividen las aguas.

Realidad natural que Holdich también constató y transformó en máxima cuando escribió: «Ni siquiera un río, una montaña, una línea de la costa, o aquella un tanto ilusoria forma geográfica que es el divortium aquarum son siempre y en todas partes inequívocamente reconocibles» (Holdich, 1958, p. 44). Proyectando así una de las particularidades de los Andes como principio geográfico; pasando de la naturaleza, de la geografía material que apreció, a los preceptos geográficos, a lo abstracto.

Todo el proceso de discusión y fijación de la frontera entre Argentina y Chile, iniciado ya en 1847 con el reclamo argentino por el establecimiento del chileno Fuerte Bulnes en una de las orillas del estrecho de Magallanes, y culminado en lo que a nuestro trabajo se refiere con el fallo del árbitro en 1902, dio lugar a una muy abundante y heterogénea documentación compuesta por los más diversos tipos de escritos, textos, cartografía, imágenes, ilustraciones y fotografías, entre otros muchos testimonios de los estudios, exploraciones, argumentos, contra argumentos, antecedentes, viajes, opiniones, palabras y conceptos relacionados con el objeto principal de la disputa, esto es, la orografía de la cordillera de los Andes, cuya determinación definiría soberanías. Todos vestigios, testimonios, fuentes, expresiones, representaciones de un hecho, suceso histórico concreto, la delimitación fronteriza entre Chile y Argentina; pero también de una realidad política y científica, incluso epistemológica, que trasciende épocas y contextos particulares, y que dice relación con las condiciones y condicionamientos de generación del conocimiento pretendidamente científico, y por tanto universal, que, como el ejemplo que ofrecemos, y como todo saber, depende estrechamente del contexto, en este caso representado por los intereses nacionales de los estados en conflicto; situación que limita, cuando no condiciona, su pretensión de «objetividad» y, por lo tanto, uno de los atributos que lo hace científico.

En el contexto de la historia cultural y de la historia social de la ciencia lo señalado no resulta novedoso. Hace rato que los estudiosos saben que prácticamente todo conocimiento es una construcción cultural; una 
mediación, una interpretación, una verdadera traducción cultural, condicionada por el medio, el contexto del que forman parte los sujetos. Pero otra cosa es que apliquemos estas nociones para explicar y comprender la realidad histórica latinoamericana en general o, en particular, a uno de los ámbitos en que las necesidades del Estado y la nación más han contribuido a naturalizar, a transformar en verdad absoluta, dogma, hito indispensable de la formación nacional, como lo es todo lo relacionado con la soberanía territorial.

Nuestro ejercicio, se produce en tiempos en que las polémicas entre estados sobre reclamos soberanos se materializan en numerosas demandas ante la Corte Internacional de La Haya para reivindicar territorios, en las que los argumentos, políticos, jurídicos, históricos, geográficos y científicos se suceden y esgrimen como "verdades» definitivas. Naturalmente fruto de investigaciones serias, con la aspiración, como expresó recientemente el coordinador histórico de la defensa de Chile en La Haya ante la demanda de Bolivia, «que cuando Chile use el argumento histórico, no lo use en términos apologéticos, de un chovinismo radical, sino maduros, que se puedan sostener entre historiadores profesionales» ${ }^{3}$.

Una intención loable que la experiencia histórica, a propósito de las controversias limítrofes chilenoargentinas, muestra prácticamente imposible, en este caso por las polisémicas formas que presentan y se atribuyeron a los Andes; aunque también porque los intereses políticos nacionales modifican la «realidad», sea esta histórica, geográfica o jurídica, adaptándola a sus necesidades, disputando no solo un territorio, sino que en definitiva un saber, pues, en este caso, lo que se entendiera por "Andes», sería lo que definiría más o menos espacios soberanos ${ }^{4}$. Constatación imprescindible de atender para identificar y comprender las alternativas y la prolongación de las querellas limítrofes chileno-argentinas, pero también como requisito epistemológico básico de una práctica analítica de la Historia de la Ciencia.

Tal vez una perspectiva como la señalada explique que en la actualidad, 2016, todavía existan espacios no delimitados en los Andes Patagónicos. Así ocurre en los llamados Campos de Hielo Sur o hielo continental patagónico, según si lo nombran Chile o Argentina, donde todavía hay 60 kilómetros aproximadamente en que la frontera chileno-argentina permanece indefinida ${ }^{5}$. Reflejo de una región que por sus características naturales, desde tiempos inmemoriales, se resiste a ser reducida solo a unos trazos en un mapa o a unas líneas en un tratado, dando lugar por el contrario a una larga disputa por el territorio y por el saber que lo determina como tal y lo caracteriza.

\section{ANDES AMBIGUOS Y POLISÉMICOS}

Cuando el Tratado de Límites firmado entre Chile y Argentina el 23 de julio de 1881 asienta que el «límite entre Chile y la República Argentina es, de Norte a Sur, hasta el paralelo cincuenta y dos de latitud, la Cordillera de los Andes»; y que "la línea fronteriza correrá en esa extensión por las cumbres más elevadas de dicha Cordillera que dividan las aguas y pasará por entre las vertientes que se desprenden a un lado y otro", no sólo esta dando origen a una fuente de controversias que se mantiene hasta la actualidad; también está recogiendo una historia de exploraciones y reconocimientos geográficos terrestres y marítimos que tuvieron como preocupación principal el macizo cordillerano. Sólo así se explica que el documento concebido para establecer una frontera unívoca, en realidad nombre cuatro posibles límites: la cordillera de los Andes, una línea que puede correr por las más altas cumbres, por la divisoria de las aguas, o por la formada por las vertientes que se desprenden a un lado y otro.

Aunque los protagonistas de las polémicas fronterizas en el cambio de siglo entre el XIX y el XX justificaron sus diferencias en las disímiles interpretaciones sobre cuál era la verdadera línea fronteriza, el curso u orientación real de los llamados Andes, o la ignorancia geográfica respecto de la zona controvertida, todo lo cual efectivamente fue discutido, lo cierto es que para los naturalistas y aventureros que exploraron los Andes a lo largo del siglo XIX era evidente que los Andes no sólo tenían múltiples formas, también que sus más altas cumbres no siempre dividían las aguas, y así lo asentaron en las descripciones, informes, estudios e ilustraciones en que dieron cuenta de sus experiencias y observaciones.

Las palabras y términos utilizados para aludir al multiforme fenómeno natural que exploraron son elocuentes: "cordillera», "Andes», "cordillera de los Andes», "cumbres más elevadas», "divisoria de las aguas», "vertientes que se desprenden a los lados», "cordilleras horizontales», "cordillera continua», "hileras de cordilleras», "montañas inferiores», "terrenos elevados», "cordillera exterior», «cordilleras distantes», "cordillera principal», "cordillera central», "gran línea central», "espina dorsal de América», «contrafuertes de la cordillera», "desfiladeros», «macizo monolítico», «eje central dominante», «masa central», «encadenamiento principal», «divisoria principal», 
"estribaciones de las montañas», "ramificaciones», "estructura de la cordillera», "encadenamiento principal orogénico», "confusión de rocas», "sistemas de cordilleras», "eslabones occidentales», "línea central de solevantamiento» y «lomo de los Andes»" ${ }^{6}$. Y todavía podría seguir citando términos utilizados en el siglo XIX para aludir al fenómeno natural y caracterizarlo, pasando de la orografía a la geología a medida que la controversia sobre el fenómeno natural obligó a los contradictores a extremar y profundizar en los recursos y argumentos para fundar sus posiciones.

Antes, cuando lo que terminaría siendo una álgida discusión todavía no se vislumbraba, aunque se tenía conciencia de la importancia del tema, los testimonios de quienes alcanzaron hasta las cumbre de los Andes, por ejemplo el reconocido naturalista Ignacio Domeyko, reflejan el saber que la exploración de la cordillera permitía ir acumulando. Domeyko, quien no sólo desarrolló su trayectoria como científico estudiando Chile y publicando sobre su naturaleza y minerales, además fue un valorado e influyente integrante de las elites nacionales, ascendió el volcán Antuco en 1845 , con la «intención de averiguar aquí la verdadera frontera de Chile y llegar al otro lado de los Andes». EI registro de su experiencia no da lugar a interpretaciones: «En el lugar llamado La Cueva se unen dos arroyos; uno viene del Sur, de Sierra Velluda, y el otro desciende desde la línea divisoria de aguas en la cresta de los Andes, los que, según veo, están bastante lejos al este de Antuco». Una constatación importante, como lo refleja el párrafo con que continuó su relación, ahora conclusión: «Esta cresta y la línea de división de las aguas, es decir la frontera oriental de la república chilena con la vecina de Argentina, no pasan, como se cree comúnmente por las más elevadas cumbres andinas como Antuco, Sierra Velluda o Chillán, sino que están situadas bastante lejos de éstas, hacia el este» (Domeyko, 1978, pp. 757-758)7.

Lo comprobado empíricamente por Domeyko a mediados del siglo XIX se transformó en conocimiento adquirido. Incluso por científicos de otras latitudes, como J.M. Gilliss, el teniente que encabezó la expedición astronómica naval estadounidense al hemisferio sur entre 1849 y 1852, quien en Chile no sólo apreció los Andes como una "frontera natural»; también, y propósito de otra cumbre andina, El Descabezado en el centro del país, escribió: «Aquí, así como en muchos otros puntos de los Andes, los cerros que separan las aguas son invariablemente menos elevados que la línea que conectaría los grandes conos o picos» (Gilliss, 1855, p.23). Más todavía, aludiendo y corrigiendo a uno de sus antecesores, pudo asegurar que algunas de las más altas cumbres de las que Darwin consideró "cadena principal» de los Andes, "se encontraban al oeste de lo que exámenes más recientes demuestran que son sólo un espolón de la real línea divisoria de las aguas» (Gilliss, 1855, p. 19).

\section{PROYECCIÓN CIENTÍFICA DE UNA CONTROVERSIA LIMÍTROFE}

La ambigüedad y polisemia de los Andes que a lo largo del siglo XIX quedó asentada fue la base sobre la cual obraron los legisladores chilenos y argentinos para redactar el texto del Tratado de Límites de 1881. Tanto la incertidumbre que la orografía de los Andes proyectaba, como el desconocimiento geográfico de algunas de sus secciones, como los Andes Patagónicos, explican una enunciación con tantas posibilidades de interpretación como la que ofreció el artículo 10 del acuerdo limítrofe. Desde entonces, los estados no sólo disputaron kilómetros cuadrados más al oeste o más al este de la cordillera, según si seguían la tesis argentina de las más altas cumbres, o la chilena de la divisoria de la aguas; primero tuvieron que definir el "verdadero curso» de la cadena montañosa, para lo cual precisaron conocer y determinar su orografía en base a lo que observaron en terreno, y cuando eso no bastó, recurrir a la geología, a la composición y estructura interna del macizo, en una disputa científica, por el saber, que sin embargo no saldó la ciencia sino que la política a través de un árbitro, un geógrafo inglés.

Los políticos en 1881 tuvieron clara conciencia de las consecuencias que tendría la redacción del Tratado, por eso es que en el texto del acuerdo, en el artículo primero, también asentaron: "Las dificultades que pudieran suscitarse por la existencia de ciertos valles formados por la bifurcación de la Cordillera y en que no sea clara la línea divisoria de las aguas, serán resueltas amistosamente por dos peritos nombrados uno de cada parte». Confiando de este modo las superficies reivindicadas al quehacer de los expertos, los peritos; a un sabio, experimentado y hábil, a un sujeto práctico en una ciencia o arte, capaz de informar y juzgar sobre puntos litigiosos; en definitiva a un científico. Previendo, tal vez porque estaban conscientes de las múltiples "formas» cordilleranas existentes, como del desconocimiento sobre algunas secciones de los Andes, añadieron que «en caso de no arribar éstos a un acuerdo, será llamado a decidirlas un tercer perito designado por ambos gobiernos», señalando incluso el procedimiento: «de las operaciones que practiquen se levantará un acta en doble ejemplar, firmada por 
los dos peritos, en los puntos en que hubieren estado de acuerdo y además por el tercer perito en los puntos resueltos por éste». Todo, sostenemos, demostración de que el poder político anticipó que la controversia pasaría de la disputa territorial a una discusión sobre el conocimiento que, conscientes que la ciencia tiene nacionalidad, sólo podría ser resuelta por un científico ajeno a las partes. Así, el Tratado de 1881, junto con delimitar Chile y Argentina en la cordillera de los Andes, asignando territorios hasta entonces disputados como la Patagonia, estableció el mecanismo de resolución de las controversias, que siendo fronteriza y por lo tanto atribuyendo soberanías territoriales, también sería científica. La confianza en el saber, en los expertos, se expresa en que el tratado también estipuló que «esta acta -la de los peritos- producirá pleno efecto desde que estuviere suscrita por ellos y se considerará firme y valedera sin necesidad de otras formalidades o trámites. Un ejemplar del acta será elevado a cada uno de los gobiernos».

Desde otra perspectiva que también resalta la consideración que los estadistas en 1881 parecieron mostrar hacia el saber, no hay que olvidar que habían sido principios del derecho internacional, establecidos a partir de la experiencia concreta dada a conocer por exploradores y naturalistas y transformada en conocimiento, los que también ilustraron a los políticos chilenos y argentinos. Ellos determinaron el límite entre ambas repúblicas teniendo en consideración la «teoría de las cuencas hidrográficas», un concepto ampliamente sustentado desde el siglo XVIII en adelante por el geógrafo francés Phillippe Bauche, según la cual las divisorias continentales de las aguas siempre estaban ligadas a las cumbres más elevadas, en una suerte de columna vertebral de las cadenas montañosas que circundan la tierra. El problema es que en los Andes, y en particular en los Andes Patagónicos, la divisoria continental de las aguas no coincide con la línea de las cumbres más altas; resultando que el sistema natural local no calzó con la teoría científica vigente entonces y que los estadistas aplicaron en tanto conocimiento aceptado. Creando una situación que provocada por la «ignorancia/conocimiento» de la realidad geográfica de los Andes en la Patagonia, dio origen a los problemas para fijar la frontera común en ese sistema natural, pero que también proyectó el problema en términos académicos como caso de estudio para los especialistas.

Hecho interesante pues significó devolver al plano teórico, jurídico y político, la realidad natural, geográfica y material que era objeto de una de las controversias: los Andes Patagónicos. De este modo se completó un periplo circular que se planteó cuando la ciencia fue aplicada a la realidad geográfica al utilizarse en la delimitación de la frontera entre ambos países la "teoría de las cuencas hidrográficas». Esta fundamental cuestión en términos de la circulación y aplicación del conocimiento, muy propia por lo demás de las perspectivas que hace suya la historia cultural de la ciencia, puede estudiarse a partir, por ejemplo, de los textos, fuentes para nosotros, publicados en The Geographical Journal y en el Bulletin of the American Geographical Society of New York a comienzos del siglo XX. Ahí están los artículos del perito inglés Thomas $\mathrm{H}$. Holdich y del geólogo estadounidense Israel C. Russell en los cuales se deduce cómo la exploración de la Patagonia a raíz de la controversia limítrofe terminó cambiando, no solo el conocimiento científico sobre la zona, sino también principios del derecho internacional, pues el caso demostró lo inconveniente que era que los estados firmaran tratados de límites ignorando la geografía. Así, la definición de las fronteras chileno-argentina pasó a ser también un asunto de interés geográfico central, dejando de ser sólo un problema político y jurídico entre estados periféricos. Otro reflejo de la forma en que se constituye el conocimiento a escala mundial.

Otro ángulo del problema es el relacionado con la situación, condición o estatus, del conocimiento científico que en esta tarea de fijar el límite se resume en el problema de si primó más la ciencia o la nacionalidad de los peritos en la posición que adoptaron ante las cuestiones en litigio. Asuntos que hasta antes de la polémica fronteriza resultaban evidentes, como el qué era una cordillera o qué se entendía por valle, río o divisoria de las aguas, pasaron a ser controvertibles. $Y$ se puede concluir que la nacionalidad de los peritos sí subordinó sus posturas e «impresiones» como las Ilamó uno. Expresión elocuente de los condicionamientos sociales, culturales, económicos y políticos en los que se desenvuelve la ciencia, y que en este caso, además, transformaron en fundamental la opinión del árbitro inglés convocado por las partes, no ya sólo para efectos de definir la soberanía de los territorios, sino también como una opinión especializada sobre un determinado fenómeno natural.

El recurso al fallo de una potencia amiga o arbitraje para toda cuestión suscitada por la aplicación del tratado de 1881 por la que optaron Chile y Argentina debe comprenderse también en un contexto internacional que para estos estados resultaba una referencia permanente. A lo largo del siglo XIX se había tomado conciencia en Europa que «la guerra resultaba inefi- 
ciente y demasiado costosa para la resolución de las disputas», lo que explica el cada vez más frecuente uso del arbitraje como mecanismo de resolución de los conflictos nacionales (MacMillan, 2014, p. 361) ${ }^{8}$. Situación que con el tiempo, y los enfrentamientos, daría origen a un conjunto de normas e instituciones de carácter internacional, hoy materializadas en la Corte Internacional de La Haya, frente a la cual Chile ha sido convocado a litigar por cuestiones de límites por Perú y Bolivia en el siglo XXI.

A fines del siglo XIX Su Majestad Británica fue la designada por los estados para arbitrar sus querellas, y a ella se recurrió en 1898 cuando los gobiernos constataron que los peritos encargados de delimitar y demarcar la frontera común no se ponían de acuerdo. En el tribunal constituido por la reina Victoria, formado por un jurista, un militar y un geógrafo, correspondería a este último, Tomas $\mathrm{H}$. Holdich, la participación más activa, no sólo por las materias objeto de la controversia, sobre todo porque visitó la zona disputada y escribió sobre sus experiencias como árbitro.

Geógrafo de nota, prolífico, documentado y versátil autor, era una autoridad en su materia y en su época. Citado, ponderado, comentado y objeto de honores, Holdich era un geógrafo con una dilatada experiencia al momento de ser convocado para arbitrar la polémica chileno-argentina. Conocedor de numerosos países, pueblos y problemas, fue encargado de temas limítrofes en la India, integró varias comisiones en Asia central, conoció el sistema de los Himalayas, escribió libros, artículos, reseñas e informes sobre Asia, problemas limítrofes y fronteras. Experto en la India, supo valorar otras culturas y apreciar las diferencias entre ellas, como sus textos lo muestran, aunque siempre estuvo atento a los intereses del Imperio Británico. Merecedor de la Medalla de Oro de la Royal Geographical Society y Doctor Honoris Causa en Cambridge, fue una personalidad de su época que firmaba sus libros como Col. Sir y Vicepresidente de la Royal Geographical Society, pero también con títulos o condiciones como K.C.I.E. (Knight Commander of the Indian Empire).

Fruto de su experiencia en el caso que lo llevó a visitar el Cono Sur sudamericano, en su libro The Countries of the King 's Award publicado dos años después del fallo arbitral, Holdich ofreció la visión que se formó del asunto sometido a su consideración, su idea sobre las posturas de los contendientes, su apreciación de la geografía que exploró, su ponderación de los argumentos de las partes y de los actores involucrados, y su caracterización de las sociedades chilena y argentina pues, si algo distingue sus textos es que siempre consideró las culturas y las realidades político sociales de los estados involucrados en los casos que tuvo la oportunidad de conocer.

\section{LA CONTROVERSIA REPRESENTADA}

En sus remembranzas de 1929 con la descripción del conflicto entre Chile y Argentina por la demarcación de los límites entre ambos países en la Patagonia, aparecido originalmente en alemán y reeditado en 2015 como Problemas limítrofes y viajes de exploración en la Patagonia. Recuerdos de la época del conflicto fronterizo entre Chile y Argentina, Hans Steffen, el geógrafo alemán desde 1892 al servicio de Chile como perito y "asesor científico», ofreció la posición de ambos países y las determinaciones del árbitro, pero sobre todo una representación de las posturas enfrentadas que muestra gráfica y eficientemente las querellas por lo que en esencia consideró «un conflicto por la divisoria continental de las aguas en la cordillera patagónica» (Steffen, 2015,pp. 16 y 18) ${ }^{9}$. Es decir un problema geográfico cuya resolución definiría una disputa política por territorios.

Antes de sus memorias Steffen había publicado Viajes de exploración y estudio en la Patagonia Occidental en 1909-1910, un compendio con el resultado de sus comisiones para el Estado chileno en la Patagonia como encargado de estudiar el sistema andino y allegar argumentos para defender la posición chilena en la controversia con Argentina. Hecho que condicionó sus trabajos y resultados, a pesar de la pretensión de empirismo que lo animó. En su Patagonia Occidental. Las cordilleras patagónicas y sus regiones circundantes, aparecido en 1919, profundiza en sus exploraciones y ofrece referencias, antecedentes, reflexiones, notas y conclusiones respecto de la región estudiada, mostrando su profundo conocimiento sobre el área geográfica disputada.

Además de sus libros, Steffen entregó numerosos trabajos a revistas científicas sobre las regiones que exploró y sobre la posición chilena en el litigio. Un ejemplo es "La cuestión de límites chileno-argentina con especial consideración de la Patagonia», artículo publicado en 1897 en el volumen 32 del Boletín de la Sociedad de Geografía de Berlín, y que mereció un "examen crítico» a cargo de Enrique S. Delachaux, Director de la Sección Cartográfica del Museo de la Plata en la Revista de aquella institución en 1898 con el reivindicativo título de "Límites occidentales de la República Argentina. El artículo del Dr. Juan Steffen. Examen crítico ${ }^{10}$. Entre otras razones, y demostra- 
ción que la polémica que ilustramos era fronteriza pero también científica, por la opinión pública y, ante la posibilidad de un arbitraje, para «neutralizar los efectos de una propaganda», "llevar la discusión científica en el mismo terreno lejano elegido por el adversario" y hacer oír la voz de la Argentina "allá donde hasta ahora se ha acostumbrado a escuchar razones y explicaciones chilenas que, poco a poco, iban transformándose en verdades geográficas» (Delachaux, 1898, pp. 3-4).

Con la perspectiva del tiempo, radicado en Suiza, siete años antes de su fallecimiento y con la pretensión de tratar el tema con "altura de miras y cierta distancia», Steffen evocó en sus recuerdos el conflicto que se desató luego de la firma del Tratado de 1881 al agravarse las diferencias de conceptos sobre los principios básicos de la fijación de los límites ya mencionados.

Ejemplo básico de las diferencias es lo ocurrido a propósito de la fijación de un hito en la cordillera a la altura de los 340 53' de latitud sur en el paso de las Damas en marzo de 1894. Mientras el perito chileno propuso indicar en el protocolo que el lugar se consideraba como «un punto de la línea divisoria de las aguas», el argentino "exigió reemplazarlo como un punto del encadenamiento principal de los Andes», debiendo adoptarse la siguiente fórmula: que «el hito había sido erigido en el encadenamiento principal de los Andes que divide la aguas» (Steffen, 2015, p. 31). Así, y con mayor razón en una zona como la Patagonia donde los Andes no tienen una «estructura regular» y por lo tanto la línea tangible de las cumbres más altas no coincide con la divisoria continental de las aguas, las diferencias se hicieron permanentes.

Las cuestiones en debate fueron sobre el principio que cada parte consideraba debía aplicarse para la demarcación de límites, y que para Steffen y Chile era el de la divisoria de las aguas, contra la pretensión de Argentina del encadenamiento principal de la cordillera; y la existencia o no de una condición orográfica, el llamado "encadenamiento principal» por donde, sostenía el perito argentino Francisco Moreno, debía correr la línea demarcatoria. A partir de ellas, y de los significados que las partes les atribuyeron a estos fenómenos se desencadenaron una sucesión de problemas para trazar una línea limítrofe desde los $26^{\circ} 53^{\prime}$ hasta los $52^{\circ}$ Sur. Todo con el añadido de que a partir de los 40ㅇ Sur aproximadamente, el conocimiento de los Andes era escaso, prácticamente inexistente, tanto respecto de las formas principales de su relieve, como respecto de su topografía y estructura geológica.
Hans Steffen a lo largo de sus memorias ofrece numerosos ejemplos de desacuerdos entre Chile y Argentina por el trazado limítrofe en diferentes zonas de los Andes Patagónicos, los llama «problemas»: en el Tronador, en los ríos Palena, Puelo, Manso, Aysén, Frías, Baker, Chico; en las cordilleras del Puelo, Manso, Futaleufú y Palena; en el lago Cochrane-Pueyrredón; en fin, en la cordillera Norpatagónica y en la Patagonia Occidental. Los que expuso en sucesivos capítulos cuyos títulos, a través de las palabras, muestran también las posiciones enfrentadas y la acción mediadora del árbitro. Así, y según el caso que evocó, habló de "trazado», "fijación», "problemas geográficos», "estudios geomorfológicos» o «la frontera política».

Toda la evidencia expuesta llevó al árbitro Holdich a recordar que «la base fundamental de casi todas las disputas por límites en la Historia ha sido la ignorancia geográfica», que los políticos que suscribieron el Tratado de 1881 no sabían nada de geografía y no habían examinado sus países, que había "unos 1.000 kilómetros de montaña inexplorada» y que a pesar de que los Andes variaban mucho en su conformación, en particular en el extremo sur de América, se había trazado toda la frontera a lo largo de la «cadena principal de los Andes» en la línea que divide los ríos de la Argentina de los de Chile, la que por supuesto no existía, dando motivo para la querella que debió resolver ${ }^{11}$.

La Patagonia, una región desconocida e inexplorada, donde la geografía según Holdich se «basaba en suposiciones», ofreció un escenario propicio para los desencuentros por su "serie de configuraciones», las que «estudiadas con diligencia y habilidad por geógrafos eminentes de ambos bandos», concluyó, "solo probaron hasta qué extremo era posible interpretar las estipulaciones del Tratado en sentidos absolutamente divergentes y con muy distintos resultados».

Ya en su segundo viaje a la cordillera Norpatagónica a la altura de los 41은 Sur, realizado en el verano de 1893 entre los lagos Todos los Santos en Chile y Nahuelhuapi en Argentina, Steffen asentó que «la divisoria interoceánica de las aguas cuyo curso estábamos sondeando, no se conecta a ninguna de las cumbres que pudimos vislumbrar» (Steffen, 2015, p. 34). Concluyendo, después de explorar la zona, incluido el macizo del Tronador, que «la línea divisoria de las aguas debía correr en una amplia curva hacia el oriente partiendo desde el portezuelo Barros Arana; muy al contrario de la opinión generalizada de los geógrafos y en especial de los chilenos, que presumía la coincidencia de la línea de las cumbres más elevadas con la línea de la divisoria continental de las aguas» (Steffen, 2015, p. 44) ${ }^{12}$. 
Reflejo de sus trabajos en la región, que como advirtió corregía el saber geográfico precedente, fue su "Esquicio de la cordillera del Tronador», el que junto con representar la divisoria principal de las aguas, ofrece también el límite fijado por el árbitro Holdich en la zona, y por eso también las diferencias territoriales que la adopción de la postura argentina, de la chilena o la del árbitro implicaban. Ilustrando las consecuencias que la disputa por el territorio y el saber tenían en el terreno.

Mapa 1. H. Steffen: Esquicio de la cordillera del Tronador

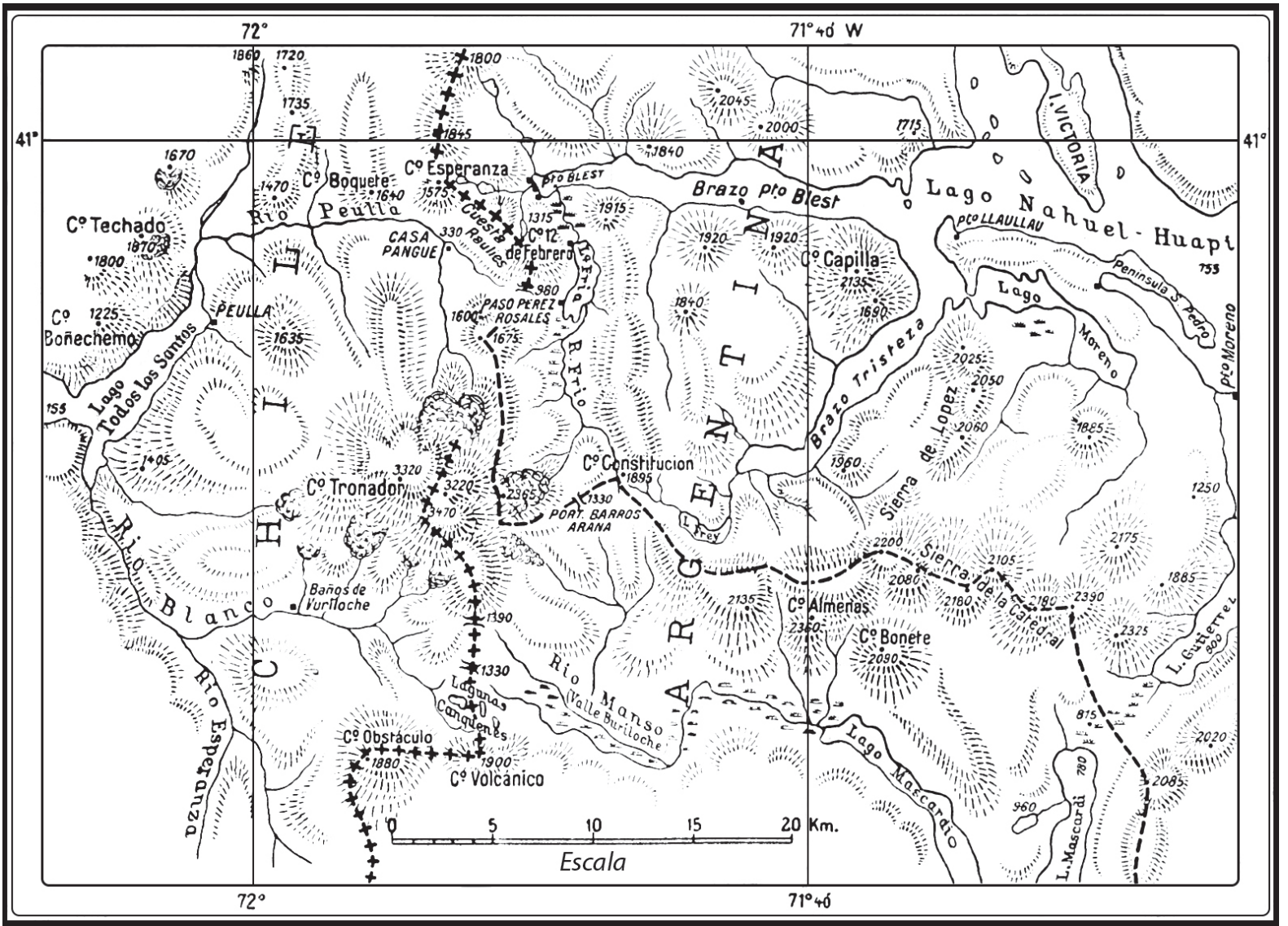

- . . . - - Divisoria principal de aguas, al sur del paso Pérez Rosales.

+++++++ Límite fijado por el Tribunal Arbitral. El tramo entre el paso Pérez Rosales y la cumbre principal del Tronador queda sin definir en detalle. C Glaciares principales.

Escala $0-20 \mathrm{~km}$.

La pertenencia de algunos valles en el borde oriental de la cordillera entre los $43 \circ$ y 440 o sur, en particular en la zona del río Palena, explicó Steffen en sus memorias, implicó resolver cuestiones previas difíciles de abordar por el desconocimiento de la región. Sobre todo el rumbo de la divisoria principal de la aguas.

Valles precordilleranos, como el 16 de Octubre y el Corinto, cuyo río no se sabía a cual sistema fluvial pertenecía, aunque se creía que a uno de la zona costera chilena, eran temas de discusión a la vez que síntomas de la incertidumbre geográfica e hidrográfica sobre ese tramo de la cordillera. Cuestión agravada por las diferencias que exploradores chilenos y argentinos de la región adyacente al paralelo 43ㅇs sur mostraban en sus textos al describir la región. Steffen exploró la cordillera del Palena en su afán por confirmar la conexión hidrográfica entre los cursos de agua situados al oriente de los Andes y aquellos que finalmente desembocaban en el Pacífico. Objetivo principal fue buscar la concordancia o identidad entre los ríos Carren- 
Mapa 2. H. Steffen: Esquicio de las cuencas subandinas de las zonas del Futaleufú y Carrenleufú (Palena)

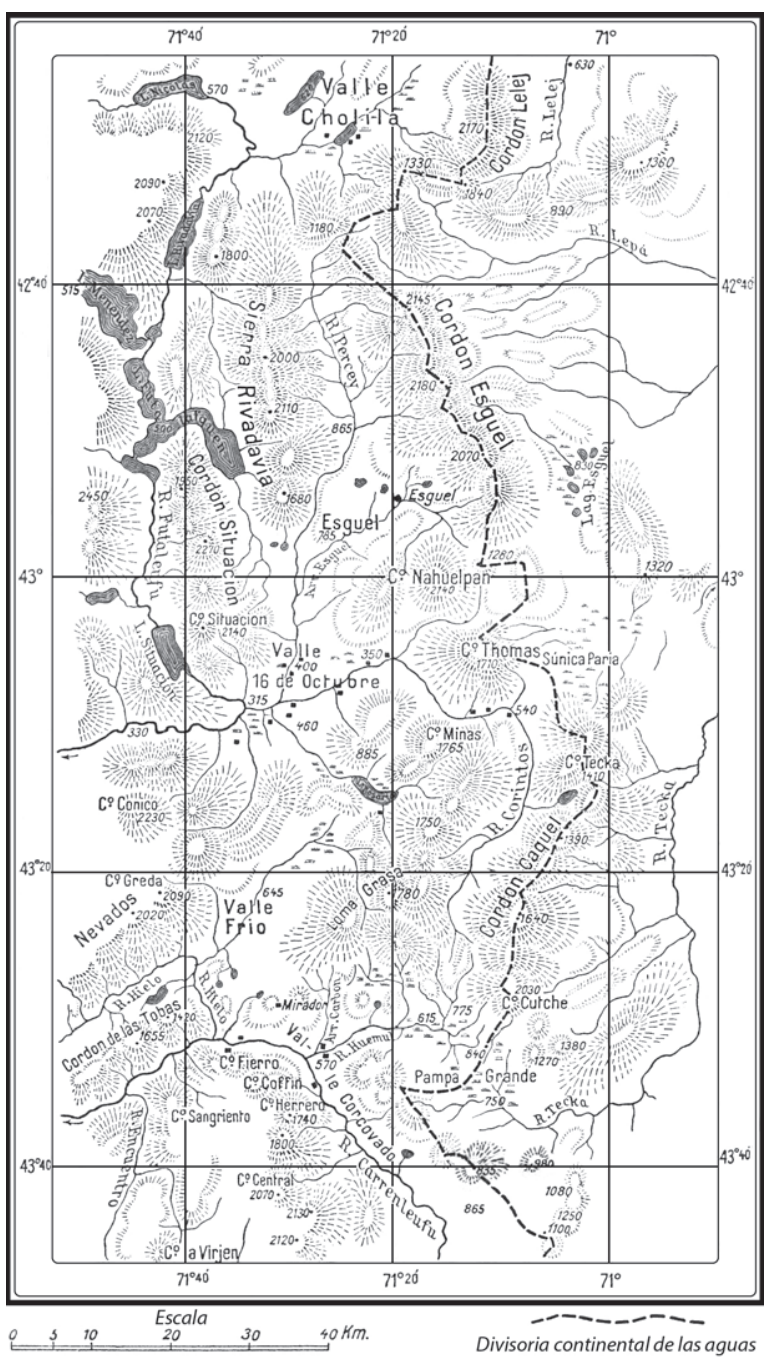

leufú y Palena, realidad que se confirmó en febrero de 1894, y que sirvió para sustentar la posición de Chile en orden a seguir la línea de la divisoria principal de las aguas para fijar el límite.

Constatación, sobre todo en lo relativo a la situación del divortium aquarum, que fue cuestionada por Francisco P. Moreno, según Steffen a causa de las deficientes descripciones y representaciones cartográficas en que se expusieron y representaron los hallazgos chilenos. El perito argentino, sin embargo, en sus Apuntes preliminares sobre una excursión a los territorios de Neuquén, Río Negro, Chubut y Santa Cruz, editados por El Museo de la Plata en octubre de 1896, y en los que describió su «reconocimiento de la región andina de la República Argentina» entre los 36ㅇ y 46ㅇ 30' de latitud sur, al oeste del 70 을 30 'de longitud oeste, concluyó que con ellos «modificaba casi completamente las ideas emitidas por los señores Serrano, Montaner, Steffen, Fischer y Stange, en sus diversas publicaciones respecto a la topografía de esas regiones» (Moreno, 1999, p. 187).

El llamado problema del río Frías refleja que la cartografía elaborada por uno y otro Estado jugó también un papel fundamental para sostener sus posiciones, sobre todo si en ella se representaban zonas desconocidas, parcialmente exploradas o respecto de las cuales no existían mapas que sirvieran de referencia. Sin perjuicio del uso y abuso de los argumentos geográficos y topográficos que entonces también fueron una estrategia para las reivindicaciones soberanas.

Según Steffen este "problema hidrográfico» se relacionaba con un río mayor que formando parte del sistema fluvial del río Palena, correría en dirección occidente. Explorado por los argentinos aproximadamente a los $44 \frac{1}{2}$ 을 de latitud sur, en 1895 se lo nombra «río Félix Frías, se sustrae de la zona del Palena y se insinúa su vinculación con el complejo lacustre de lagunas de Elizalde, dibujándolo, sobre la base de meras suposiciones, como que desagua en el río Aysén»" (Steffen, 2015, p. 129).

Para el perito chileno la representación de Moreno, que incluyó el lago La Plata, no solo creó confusión en la topografía de la cordillera entre los $44 \frac{1}{2}$ ㅇ y los 45 ㅇ de latitud sur, sobre todo implicó «el traslado de la divisoria de las aguas hacia un cordón cordillerano cercano a la costa». Un hecho alarmante para Chile pues recordó, explicando las consecuencias, «si las indicaciones de Francisco Moreno se confirmaban, se estaba ante un acercamiento extremo de una región que estaba innegablemente bajo soberanía argentina hacia la costa del Pacífico, lo que sin lugar a dudas tendría que llevar a negociaciones complicadas para preservar la soberanía de Chile sobre la costa del Pacífico, como había sido garantizado en el protocolo de 1893» (Steffen, 2015, pp. 130-133).

Las descripciones y representaciones argentinas provocaron, relató Steffen, que ante la «escasa información que en Chile existía sobre la orogenia de la cordillera y la hidrografía del interior de la zona de los fiordos entre Palena y Aysén», se organizara una expedición para «determinar la ubicación del río Frías y buscar una solución a los problemas suscitados en relación con la divisoria principal de las aguas al oeste del lago La Plata», confirmando que la controversia territorial estaba acompañada de una disputa por el saber sobre los Andes Patagónicos entre Chile y Argentina (Steffen, 2015, pp. 133-134). 
Mapa 3. H. Steffen: Fijación de límites en el río Palena

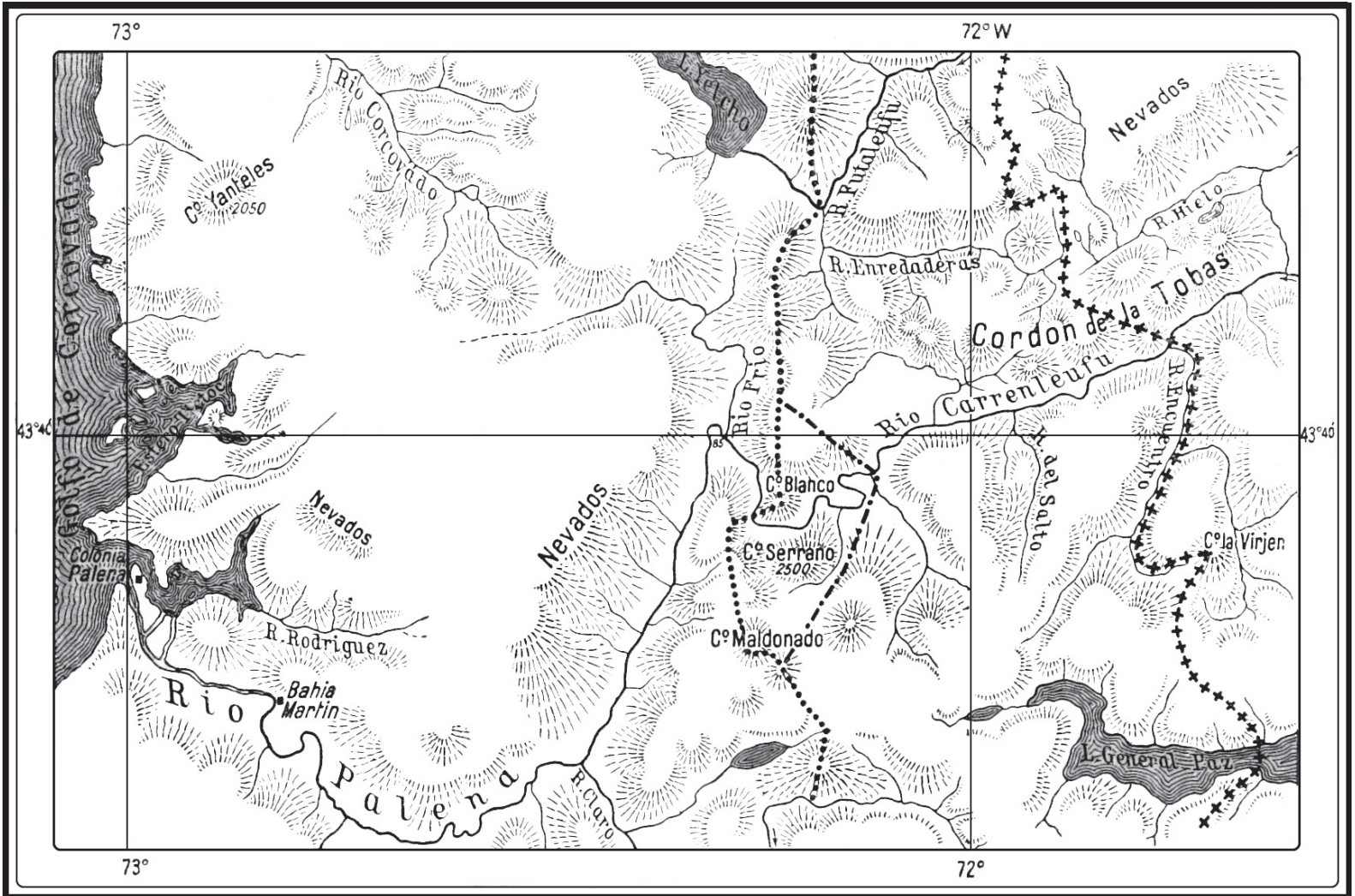

En el río Palena, la representación chilena de la geografía influyó en el trazado del límite con Argentina. ++++ Límite fijado por el Tribunal

••• Límite propuesto por Argentina en 1900

-.-.-. Variante 1898

Mapa 4. H. Steffen: El río Frías y el lago La Plata según Argentina

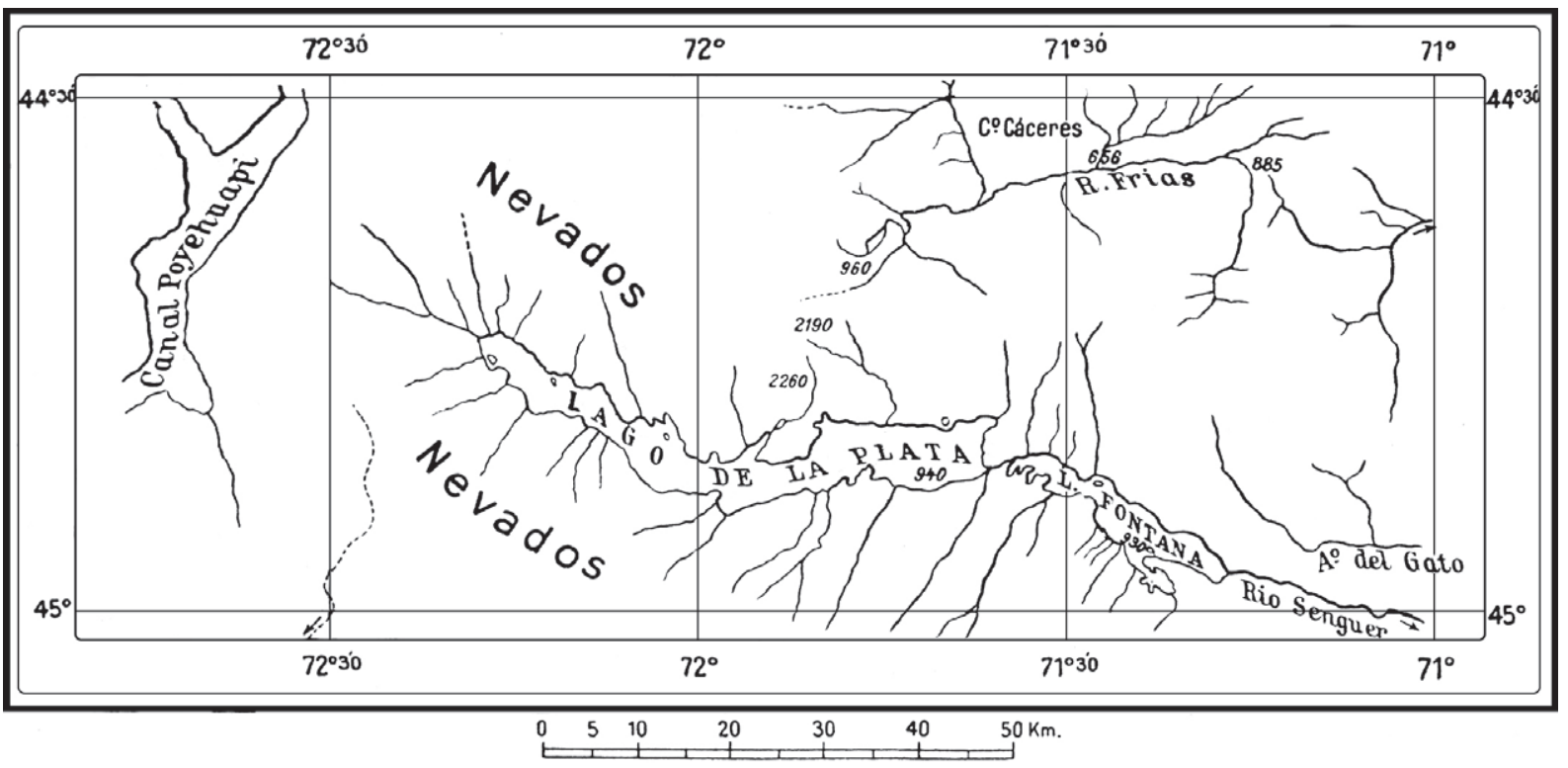

Fragmento del mapa de Francisco P. Moreno, La Plata, 1897. Escala 0 - 50 km

Mapa aparecido en el Boletín del Instituto Geográfico Argentino en 1895, y que el Perito Moreno también reprodujo para solventar sus tesis. 
La comisión estatal que encabezó Hans Steffen el verano de 1897/1898 tuvo dos objetivos, recordó el científico, reflejando de paso los esfuerzos oficiales por adelantar en los reconocimientos geográficos para fundar las reivindicaciones soberanas. Primero, determinar el curso que tomaba la línea diviso- ria de las aguas entre los lagos La Plata y Fontana, como las respectivas zonas fluviales contiguas de la costa del Pacífico; segundo, resolver el tema de la pertenencia hidrográfica del río Frías, asunto que entonces permanecía confuso a pesar de la expediciones argentinas.

Mapa 5. H. Steffen: Esquicio del río Cisnes (Frías) y de la ubicación corregida del lago La Plata

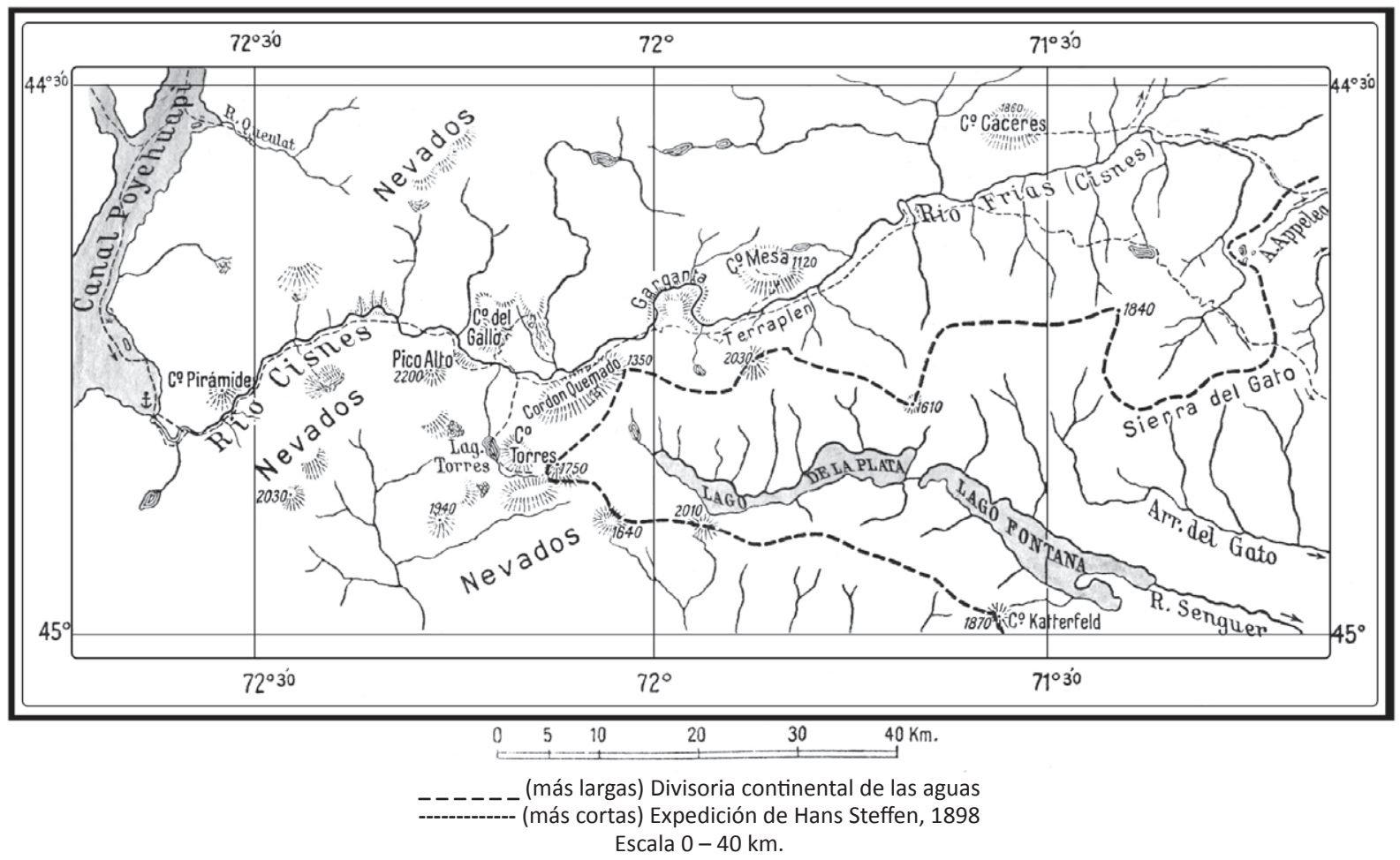

El mapa elaborado por Steffen resume las conclusiones de su exploración. Comprobó que el río Frías no era parte de la cuenca hidrográfica del Aysen y aclaró la estructura hidrográfica de la zona cordillerana entre las latitudes $44 \frac{1}{2}$ o y 45 o sur, refutando las representaciones de Francisco Moreno.

Sin perjuicio de demostrar que la ciencia en el conflicto de límites chileno-argentino sí tuvo nacionalidad, el caso de la delimitación del área adyacente al grado que va entre los 44 y 45 de latitud sur en la Patagonia ofrece también la oportunidad de explicar la forma en que el árbitro Thomas Holdich evaluó el conocimiento geográfico sobre la región producido por las comisiones de peritos de Argentina y Chile, y terminar ofreciendo una "frontera política» que no coincidía exactamente con el "principio geográfico de demarcación», ya sea que este fuera el propuesto por Argentina, altas cumbres, o el chileno, divisoria de las aguas».

\section{UN ÁRBITRO ENTRE TERRITORIOS Y SABERES}

Como Steffen reconoció, había sido la incompatibilidad de ambas propuestas lo que llevó a recurrir al tribunal inglés, el que, como asentó Holdich, siempre estuvo consciente de que la controversia de límites tuvo en los necesarios reconocimientos geográficos de las zonas en disputa un factor determinante. Es decir la soberanía condicionada al saber sobre la territorialidad reivindicada.

Para la zona del río Frías hacia el sur, entre los 44을 y los 46 o S, el geógrafo de la Royal Geographical Society reconoció que «la división continental que rodea su nacimiento se aleja de los picachos andinos, no obstante que la división de la aguas sigue siendo clara», reconociendo en su fallo las pretensiones chilenas con una mínima excepción. Justificando su determinación escribió: «La línea propuesta por Argentina atrave- 
saba los afluentes unidos del Aysén a poca distancia de la costa del Pacífico y seguía cordones cordilleranos, cuya conformación era más o menos incierta. Sin duda, aunque la divisoria continental de las aguas sea imprecisa para que sea considerada como base para un buen límite desde el aspecto topográfico en este tramo, empero es en efecto esta la mejor línea limítrofe ofrecida por la naturaleza y por cierto la única línea aplicable y natural, que no se acerca en demasía al litoral del Pacífico» (Holdich, 1958, p. 236).

Las palabras del árbitro reflejan muy bien la declaración general que precedió al fallo, donde, en la fundamentación se asentó: «En presencia de estas contenciones divergentes, después de la más cuidadosa consideración, hemos llegado a la conclusión de que la cuestión que nos está sometida no es simplemente la de decidir cuál de las dos líneas alternativas es correcta o errónea, sino más bien la de determinar - dentro de los límites definidos por las pretensiones extremas de ambas partes - la línea fronteriza precisa que, en nuestra opinión, interprete mejor la intención de los documentos diplomáticos sometidos a nuestra consideración (Steffen, 2015, p. 54).

Declaración reafirmada por Holdich en el libro que publicó en 1904 con su experiencia como árbitro en la disputa chileno-argentina, donde escribió que luego de su visita a los Andes Patagónicos, el conocimiento práctico le hizo ver «la futilidad de contemplar la infinita variedad de manifestaciones de la naturaleza como base geográfica de un acuerdo político»; concluyendo entonces que el trabajo del tribunal consistió en "pronunciar una decisión arbitral basada más bien en el espíritu del Tratado chileno-argentino que en el texto mismo» (Holdich, 1904, pp. 43 y 67).

Mapa 6. H. Steffen: Fijación de límites al norte y sur del 45오

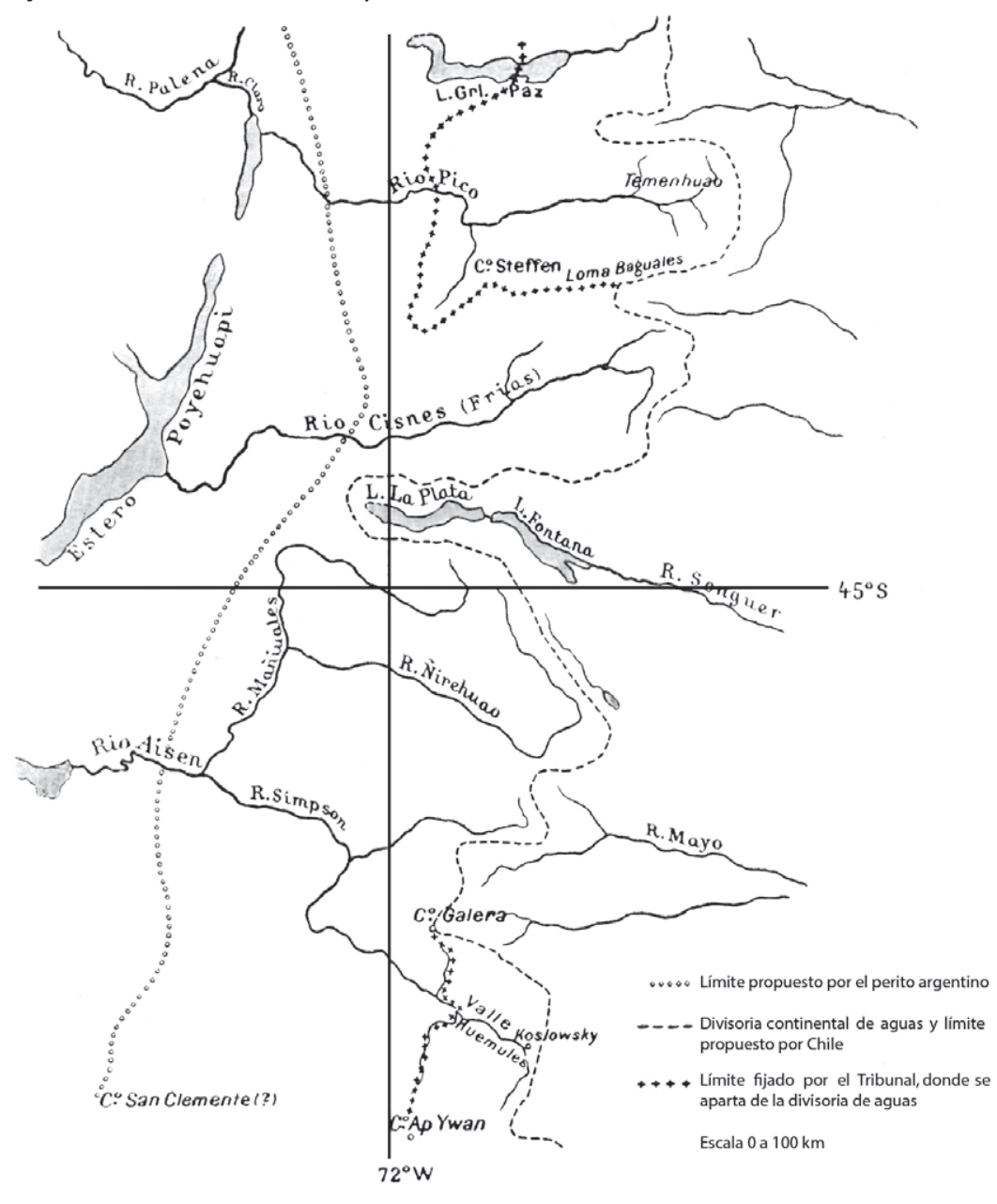

Para el tramo entre Steinfeld y Koslowsky, el árbitro consideró que «ninguna otra parte de la divisoria de las aguas es más difícil de determinar, pero era precisamente aquí en donde el interior del terreno en cuestión era de suyo inapropiado para un límite cordillerano» (Holdich, 1958, p. 235). 
La controversia chileno-argentina no quedó para Holdich sólo circunscrita a estos países, fue un caso que después el geógrafo utilizó para ilustrar problemas relativos a las fronteras y también establecer principios generales. Por ejemplo en su libro Political Frontiers and Boundary Making, en el que afirmó que en la muy escasa literatura existente sobre fronteras internacionales, no ha podido encontrar una opinión autorizada basada en experiencia práctica; agregando que el primero y gran objetivo de una frontera nacional es asegurar la paz y la buena voluntad entre los pueblos vecinos. Por eso es que en el capítulo sobre las fronteras naturales, alude a los Andes para ejemplificar el que Ilama efectivo uso de importantes cadenas montañosas como frontera en el mundo civilizado. Concluyendo que además de la ignorancia sobre las condiciones geográficas de la zona fronteriza, quizás lo peor sea una geografía imprecisa, y que indudablemente, en la historia reciente, el ejemplo más notable de esta forma errónea de delimitación, alentada por un antagonismo peligroso, es el que afloró entre dos grandes repúblicas sudamericanas, Argentina y Chile a propósito de la partición de la Patagonia (Holdich, 1916, pp. $148-150$ y $186-190)$.

\section{COLOFÓN}

El artículo primero del tratado chileno-argentino de 1881 ofrece un potencial ilimitado para la práctica de la historia cultural de la ciencia, aquella que además se ocupa del contexto social en el que se practica, produce y aplica el conocimiento; pero también de la geografía histórica pues, en definitiva, todo lo obrado por los peritos y las comisiones que constituyeron, significó abordar y resolver un problema geográfico, intelectual, que tuvo repercusiones en la sociedad y terminó siendo objeto de representaciones cartográficas que evolucionaron en el tiempo, cambiando así el espacio. En este caso de una y otra república.

Si en una primera instancia se puede creer que una montaña resulta ser el símbolo mismo de lo cierto, lo definitivo e inamovible, pues una cordillera es una cordillera y no admite discusión sobre sus características y contornos, menos en una época como el siglo XIX en la que el positivismo descriptivo dominaba la ciencia geográfica con sus definiciones contundentes y ajenas a todas especulación crítica, la realidad es que para el caso de los Andes los firmantes del tratado pensaron, creyeron o supusieron otra cosa, tal vez por el desconocimiento existente entonces sobre las características del macizo andino. De otra manera no se entendería que, inmediatamente a continuación de señalar la cordillera como frontera, un «límite inconmovible» y a "perpetuidad», como se lee en el artículo sexto del convenio, se asentase que "las dificultades que pudieran suscitarse», precisamente por establecer la montaña como lindero, «serán resueltas amistosamente por dos peritos». Apareciendo así la figura del perito al que el poder político le entregó el trabajo de establecer/proponer los espacios nacionales. Es la ciencia concebida al servicio de la soberanía territorial y por lo tanto del poder y su afán por conocer y dominar.

La prevención realmente anticipatoria de las controversias que vendrían y que se prolongan hasta hoy, se origina en que el tratado estipuló que "la línea fronteriza correrá por las cumbres más elevadas de dicha cordillera que dividan las aguas y pasará por entre las vertientes que se desprenden a un lado y otro». Una breve frase de dos líneas que no sólo reconocía diversos fenómenos naturales para establecer el lindero, sino que dio pie a posibles interpretaciones sobre lo que se entendería por «la línea fronteriza», que sólo el conocimiento, la ciencia, los peritos, podrían determinar. Aunque finalmente serían los políticos quienes decidirían.

Que ya entonces las posibles formas de establecer el límite chileno-argentino se conciben incompatibles y sólo capaces de resolver gracias a la práctica científica, lo demuestra el hecho que en el Tratado de 1881 se identifique con claridad las dificultades que surgirán de la aplicación de la convención por «la existencia de ciertos valles formados por la bifurcación de la cordillera y en que no sea clara la línea divisoria de las aguas». Así queda en evidencia que los representantes de los gobiernos al menos preveían las complejas características de los Andes por el conocimiento acumulado sobre la cordillera.

En una redacción que resulta esencial para justificar nuestro texto, el artículo primero del convenio chileno-argentino alude a «las operaciones que practiquen" los peritos encargados de dirimir las controversias. Una labor que no estuvo ajena a las controversias, y no ya sólo limítrofes, sino que también científicas pues, en definitiva, tras cada una de las posturas hubo concepciones sobre los fenómenos naturales, modos de practicar la ciencia, métodos y medios, así como experiencias nacionales en relación con el conocimiento, que determinaron el resultado final de la tarea prevista en el tratado. La que a su vez sólo pudo ser concluida, o adelantada, 
gracias a la participación de un tercero, el árbitro, que introdujo otra tradición cultural, política y científica, la inglesa que, en este caso, debió mediar en lo que para Holdich era «el aspecto más interesante del problema limítrofe en estos tiempos, esto es, la conexión inseparable que existe entre los convenios fronterizos y el conocimiento geográfico práctico» (Holdich, 1904, p. 69). Es decir, la relación entre ciencia y política, entre territorio y saber en disputa, que la zigzagueante frontera trazada por el árbitro entre Chile y Argentina en los Andes Patagónicos refleja elocuentemente.

\section{Mapa 7. H. Steffen: Mapa sinóptico de la Patagonia Occidental}

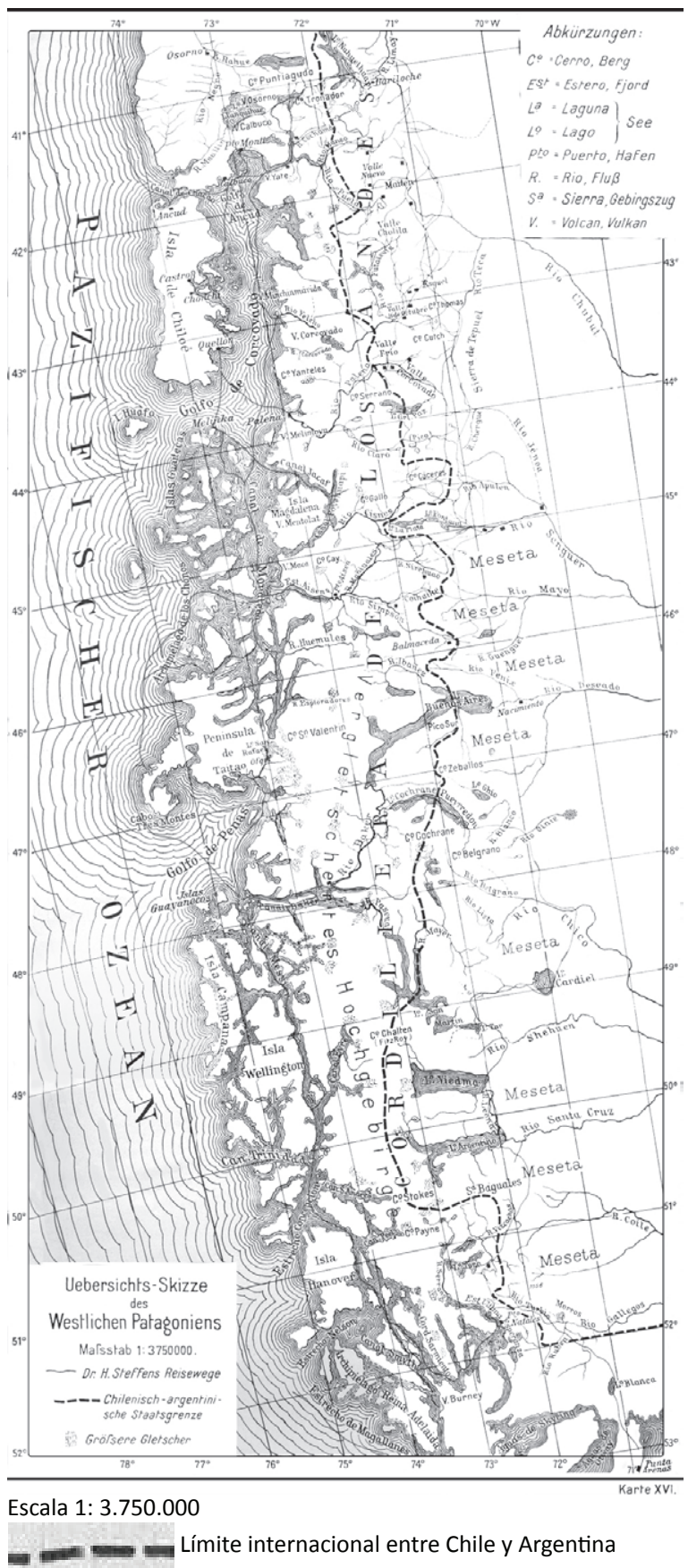

\section{NOTAS}

1. Preparado en el contexto de los proyectos FONDECYT № 1130515 (Chile), "Los hombres de los límites. La delimitación y demarcación de la frontera chileno-argentina. 1881-1908", y HAR2013-48065-C2-2-P (España), "Ciencia y espectáculo de la naturaleza. Viajes científicos y museos de historia natural.

2. Citamos de la traducción del libro de Holdich, publicada como ¿Territorio en disputa? Ensayo, p. 43.

3. Entrevista a Joaquín Fermandois, en EI Mercurio, "Reportajes", Santiago, 25 de octubre de 2015 , p. 8 . A propósito de las querellas por derechos de soberanías territoriales de los estados, la mayor parte de las cuales se fundan en el principio "como poseías, seguirás poseyendo", elocuente resulta la conclusión de Marta Lorente en la frase final de su agudo texto "Uti possidetis, ita dominis eritis. Derecho internacional e historiografía sobre el territorio", donde asienta que cada vez que se invoca el uti possidetis, "este no remite a la historia del territorio para solucionar las disputas, sino que, por el contrario, la crea".

4. En junio de 2016 Chile demandó a Bolivia ante la Corte Internacional de La Haya buscando que esta reconozca que el Silala es un río de curso internacional y que por lo tanto Chile tiene derechos sobre ese curso de aguas que, naciendo en Bolivia, se desplaza hacia el oeste, corriendo por territorio chileno. Se adelantó así a una demanda boliviana ante la misma Corte para que esta reconociera que es un manantial que fue desviado artificialmente hacia Chile. Ahora Bolivia presentará una contrademanda con su reivindicación. En este caso, como en el que tratamos, la discusión por el derecho al uso del agua del Silala, un tema de soberanía, estará supeditada a una cuestión geográfica y geológica: ¿el Silala es río o manantial?

5. El área sin demarcación de límites está ubicada entre los paralelos $49^{\circ} 10^{\prime} 00^{\prime \prime}$ y $49^{\circ} 47^{\prime} 30^{\prime \prime}$ de latitud sur y los meridianos $73^{\circ} 38^{\prime} 00^{\prime \prime}$ y $72^{\circ} 59^{\prime} 00^{\prime \prime}$ de longitud oeste, es un territorio rectangular que va desde pocos kilómetros al norte de la cumbre del monte Fitz-Roy hasta el cerro Murallón.

6. Todos las palabras citadas están en los escritos producidos por los siguientes exploradores, naturalistas, hidrógrafos y aventureros que a lo largo del siglo XIX se aventuraron a recorrer, cruzar, estudiar y visitar los Andes: (Fitz-Roy, 2013; Charles Darwin, 2009; Domeyko, 1843; Domeyko, 1875; Domeyko, 1978; Philippi, 2008; J.M. Gilliss, 1855; Simpson, 2011; Steffen, 2009; Holdich, 1904; Holdich, 1916; Holdich 1958). Por eso están entre comillas. Los utilizados están identificados en la bibliografía. 
7. Los recuerdos de Domeyko aparecieron el año 1978 como Mis viajes. Memorias de un exiliado.

8. El recurso del arbitraje fue el utilizado por Argentina y Chile para resolver sus controversias de límites en el cambio de siglo entre el XIX y el XX. Esta determinación mereció elogios del árbitro inglés que medió entre las partes: "El recurrir al arbitraje y no a las armas marca una nueva era en la historia de las repúblicas de Sudamérica. Este acto colocó a ambos países en una posición moral más elevada dentro de todas las naciones que la más ventajosa de las guerras. Argentina y Chile han dado una lección al resto del mundo". Los conceptos del reconocido geógrafo Thomas H. Holdich datan de 1904.

9. Para una aproximación a las tareas de Steffen, véase Carlos Sanhueza (2014), Geografía en acción. Práctica disciplinaria de Hans Steffen en Chile (1889-1913).

\section{BIBLIOGRAFÍA}

Darwin, Charles (2009), Diario del viaje de un naturalista alrededor del mundo, Madrid, Espasa Calpe.

Delachaux, Enrique S. (1898), Límites occidentales de la República Argentina. El artículo del Dr. Juan Steffen. Exámen crítico, La Plata, Revista del Museo de La Plata, Talleres de Publicaciones del Museo.

Domeyko, Ignacio (1843), Excursión a las cordilleras de Copiapó. Con una breve exposición de los principios fundamentales de la jeología de Chile, Santiago, Imprenta del Estado.

Domeyko, Ignacio (1875), Jeografía jeológica. Estudio del relieve o configuración exterior del territorio chileno con relación a la naturaleza jeológica de los terrenos que entran en su composición, en Estudios jeográficos sobre Chile. Memorias relativas a varias cuestiones sometidas al congreso internacional de ciencias jeográficas de París de 1875, Santiago, Imprenta Nacional, pp. 47-81.

Domeyko, Ignacio (1978), Mis viajes. Memorias de un exiliado, Santiago, Ediciones Universidad de Chile.

EIMercurio, “Reportajes", Santiago, 25 de octubre de 2015, p. 8, [en línea], disponible en: http://impresa.elmercurio.com/Pages/ NewsDetail.aspx?dt $=25-10-2015 \% 200: 00: 00 \& N e w s I D=356$ $111 \& d t B=30-07-2016 \% 200: 00: 00 \&$ Body $\mid D=10 \&$ Paginald $=8$ [consultado el 03/01/2016].

Fitz Roy, Robert (2013), Viajes del 'Adventure' y el 'Beagle'. Diario, Madrid, Catarata, DIBAM, UNAM, UACH, CSIC.

Holdich, Sir T.H. (1991), "My Life Story". En: el sitio web The Holdiches, The Holdich Family History Society, [en línea], disponible en: http://www.holdiches.com/sir-thomas-hungerford-holdich-1843-1929/my-life-story-part-6/ [consultado el 09/06/2016].
10. El texto de Steffen fue reproducido por Delachaux y publicado también en los Anales de la Universidad de Chile, volumen 94, № 22-23, 1936.

11. Sir T.H. Holdich, "My Life Story", en el sitio web The Holdiches. The Holdich Family History Society, http://www.holdiches. com/sir-thomas-hungerford-holdich-1843-1929/my-life-storypart-6/, visitado el 9 de junio de 2016. Se trata de unas memorias que como su autor advierte fueron escritas para el beneficio de sus nietos, y en las que se explaya con toda confianza en lo que describe como un breve esbozo de su vida.

12. En diversas publicaciones, como Límites con la República Argentina (1895) y Memoria e informe, relativo a la Expedición Exploradora del río Palena (1895), Steffen y otros habían dado a conocer los resultados de sus comisiones.

Holdich, Thomas H. (1916), Political Frontiers and Boundary Making, Londres, MacMillan and Co., Limited.

Holdich, Thomas H. (1958), ¿'Territorio en disputa? Ensayo, Santiago, Editorial del Nuevo Extremo.

Holdich, Thomas H. (1904), The Countries of the King's Award, Londres, Hurst and Blackett, Limited.

Gilliss, J.M. (1855), The U.S. Naval Astronomical Expedition to the Southern Hemisphere During the year 1849-'50-'51-'52, Washington, A.O.P. Nicholson, Printer.

Lorente, Marta (2014), "Uti possidetis, ita dominis eritis. Derecho internacional e historiografía sobre el territorio", ISTOR: Revista de historia internacional, 15 (59), pp. 155-194, [en línea], disponible en: http://www.istor.cide.edu/revistaNo59. html [consultado el 21/06/2016]

MacMillan, Margaret (2014), 1914. De la paz a la guerra, Madrid, Turner Noema.

Moreno, Francisco P. (1999), Apuntes preliminares sobre una excursión a los territorios de Neuquén, Río Negro, Chubut y Santa Cruz, Buenos Aires, El Elefante Blanco. (1a Edición 1897).

Philippi, Rodulfo Amando (2008), Viaje al desierto de Atacama. Hecho por orden del gobierno de Chile en el verano de 185354, Santiago, Dirección de Bibliotecas, Archivos y Museos, Pontificia Universidad Católica de Chile y Cámara Chilena de la Contrucción.

Sanhueza, Carlos (2014), Geografía en acción. Práctica disciplinaria de Hans Steffen en Chile (1889-1913), Santiago, Editorial Universitaria.

Simpson, Enrique M. (2011), Viajes de exploración por los archipiélagos australes, Chile, Ofqui Impresores. 
Steffen, Hans (1929), Grenzprobleme und Forschungsreisen in Patagonien. Erinnerungsblätter aus der Zeit des chilenisch-argentinischen Grezkonfliktes, Stuttgart, Strecker und Schröder Verlag/Stuttgart.

Steffen, Hans (1936), "Los cerros de las islas de los canales occidentales de la Patagonia, ¿forman parte de la cordillera de los Andes?", Anales de la Universidad de Chile, Santiago, 2223, pp. 232-241.

Steffen, Hans (2009), Patagonia Occidental. Las cordilleras patagónicas y sus regiones circundantes, Santiago, La Silla Editores.
Steffen, Hans (2015), Problemas limítrofes y viajes de exploración en la Patagonia. Recuerdos de la época del conflicto fronterizo entre Chile y Argentina, Santiago, Centro de Investigaciones Diego Barros Arana de la Dirección de Bibliotecas, Archivos y Museos y Nativa Ediciones. Traducción y notas al margen de Fresia Barrientos y Wolfgang Staub.

Steffen, Hans (2010), Viajes de exploración y estudio en la Patagonia Occidental. 1892-1902, Santiago, Dirección de Bibliotecas, Archivos y Museos, Pontificia Universidad Católica de Chile y Cámara Chilena de la Construcción. 